\title{
Intensification of methane production from waste frying oil in a biogas-lift bioreactor
}

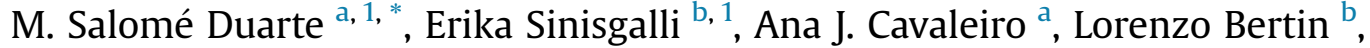 \\ M. Madalena Alves ${ }^{a}$, M. Alcina Pereira ${ }^{a}$ \\ ${ }^{a}$ CEB - Centre of Biological Engineering, University of Minho, Campus de Gualtar, 4710-057, Braga, Portugal \\ ${ }^{\mathrm{b}}$ University of Bologna - Alma Mater Studiorum, Department of Civil, Chemical, Environmental, and Materials Engineering, Via Terracini 28, 40131, \\ Bologna, Italy
}

\section{A R T I C L E I N F O}

Article history:

Received 7 October 2020

Received in revised form

22 December 2020

Accepted 27 December 2020

Available online 31 December 2020

\section{Keywords:}

Biogas upgrading

Biogas-lift bioreactor

Waste-frying oil

Anaerobic digestion

\begin{abstract}
A B S T R A C T
Biogas upgrading from anaerobic digestion of waste frying oils (WFO) was accessed in this study. For that, two bioreactors (Rb-biogas-lift bioreactor with gas and liquid recirculation, Rc-control reactor with liquid recirculation) were fed three times per week, with a mixture of WFO, glycerol and volatile fatty acids (VFA). Rb produced 1.4 times more biogas with higher methane content (79\%) than Rc (67\%). Higher relative abundance of hydrogenotrophic methanogens (34\%-39\%) was observed in $\mathrm{Rb}$, when compared to Rc $(16 \%-21 \%)$. The relative abundance of Sprochaetia class, which includes some homoacetogens/ syntrophic acetate oxidizing genera, was also higher in $\mathrm{Rb}$. This work shows that biogas recirculation applied in the biogas-lift bioreactor facilitated WFO degradation, most probably due to the selective enrichment of hydrogenotrophic methanogens. Recirculation of $\mathrm{CO}_{2}$ present in the biogas and reverse homoacetogenesis (i.e. syntrophic acetate oxidation) seem to be the main factors involved in the stimulation of hydrogenotrophic methanogenesis.
\end{abstract}

() 2020 Elsevier Ltd. All rights reserved.

\section{Introduction}

The UN Sustainable Development Goals (2030 Agenda) urge to promote the access to clean energy research and technology, including renewable energy, energy efficiency and advanced and cleaner fossil-fuel technology [1]. Moreover, this Agenda also encourages the environmental management of wastes and wastewater in order to minimize their adverse impacts on human health and the environment. Targeting these goals, anaerobic digestion $(\mathrm{AD})$ is a promising approach that treats waste/wastewaters, minimizing their release into the environment while promoting the recycling of nutrients and producing a source of renewable energy - biogas.

Biogas is composed mainly by carbon dioxide (30-50\%) and methane (50-70\%), and may contain several trace compounds depending on the organic source [2]. The relative high amounts of carbon dioxide in biogas considerably decreases its calorific value [3]. Therefore, biogas upgrading techniques, which aim to increase

\footnotetext{
* Corresponding author.

E-mail address: salomeduarte@ceb.uminho.pt (M.S. Duarte).

1 Contributed equally to this paper.
}

the relative concentration of methane in the biogas by removal and/ or transformation of carbon dioxide, are important emerging technologies [2]. At the moment, physical/chemical technologies of biogas upgrading are mainly based on the separation of carbon dioxide from methane by using membranes or absorption/ adsorption processes [4]. For example, the use of membranes in $\mathrm{CO}_{2}$ abatement is a relatively novel approach, in which the gas molecules are selectively separated from their mixture using a membrane [5]. Additionally, in the case of a membrane contactor, this process combines the membrane (acting as a gas/liquid interface) and adsorption [5]. Nevertheless, the biological approaches, when compared to physical/chemical technologies, present the major advantage of converting the $\mathrm{CO}_{2}$ into high added-value products at mild operational conditions, such as atmospheric pressure and moderate temperature [4]. Therefore, these bio-technologies present a lower energetic cost, being more eco-friendly and promoting a bio-based economy [4].

In this work, we hypothesize that biogas recirculation may be a practical, easy and cost-effective technique to improve the quality of the biogas itself. The re-introduction of biogas containing $\mathrm{CO}_{2}$ may stimulate the consumption of this component by, for example, the hydrogenotrophic methanogens, and therefore increase the 
methane content in the biogas. Alternatively, it may favour the use of $\mathrm{CO}_{2}$ as substrate by homoacetogenic bacteria, producing acetate that will be further used by acetoclastic methanogens to produce methane. Up to now, this strategy has been seldom studied. For example, in a study that focused on bioupgrading syngas into biogas (mainly methane) via anaerobic fermentation, the gas recirculation in the reactor allowed for a higher nutrients and carbon source availability, resulting in a CO conversion efficiency higher that in the absence of gas recirculation [6]. Also, for ex situ biogas upgrading $\left(\mathrm{CO}_{2}\right.$ is provided from external sources), the increment of gas recirculation flow rate increased the methane content in the biogas [2,7].

Lipid-rich wastes, such as waste frying oil (WFO), are valuable resources with high energy content [8]. WFO results from the process of food frying, and its inadequate disposal through sewage systems causes economic and environmental problems. Besides other possible alternatives, such as the conversion of WFO into liquid fuel and other added-value chemicals, AD of WFO appears to be a relevant solution to prevent the release of this waste into the environment and to obtain value (as biogas) from it. The valorisation of WFO through AD may also be a good strategy in specific contexts where biodiesel production from waste oil is not an option. WFO are mainly composed by triglycerides (95-96\% of the edible oils) and those are generally accompanied by small amounts of mono/diglycerides, free fatty acids, phospholipids, sterols, and hydrocarbons [9]. In AD, triglycerides are first hydrolysed to glycerol and long-chain fatty acids (LCFA) [10]. Usually, palmitic, oleic, and linoleic acids are the main LCFA present in oils and fats [11]. Glycerol is then converted to acetate by acidogenic bacteria, while LCFA are converted to acetate and hydrogen through the $\beta$-oxidation pathway $[12,13]$. The $\beta$-oxidation is performed by syntrophic bacteria and this process is thermodynamically dependent on the activity of hydrogen scavengers, namely hydrogenotrophic methanogens, that will reduce the hydrogen partial pressure and therefore allowing the LCFA degradation [8]. Ultimately, both acetate and hydrogen are converted to methane by methanogenic archaea.

Despite its high potential for biomethanation, lipids/LCFA biodegradation is a difficult and slow process since these compounds are poorly soluble, may cause microbial inhibition (specially towards the methanogens) and adsorb to the sludge, which often causes sludge washout and mass transfer limitations (therefore affecting microbial metabolism) [10,14,15]. Biogas recirculation may also improve the mixing [16], which is an important feature in the $\mathrm{AD}$ of WFO, since mixing may promote the contact between the hydrophobic substrate and the microbial community. Gas bubbles promote a gentler mixing when comparing with other methods, such as mechanical agitators [9], which represents a critical issue, in preserving the syntrophic relationships based on close proximity of bacterial and archaeal cells, needed for lipid/ LCFA degradation [17].

In this work, WFO was chosen because it is a lipid-rich waste, thus presenting higher methane potential (when compared to proteins and carbohydrates), and because lipids/LCFA biodegradation is generally a difficult and slow process as previously mentioned [18]. Therefore, we aimed to test the targeted hypothesis, but also simultaneously to develop a novel strategy of intensifying the conversion of difficult lipid-rich substrates to methane. For that, the conversion of WFO to methane is studied in a biogaslift reactor $(\mathrm{Rb})$, operated with biogas and liquid recirculation, and compared with a control reactor ( $\mathrm{Rc}$ ) operated only with liquid recirculation. Both reactors were inoculated with the same sludge, which was previously acclimatized to WFO substrate. Reactors' performance was followed by measuring the cumulative biogas production and its methane content, as well as volatile fatty acids
(VFA) and LCFA concentrations. At the end of the experiment, the microbial communities present in both reactors were analysed.

\section{Materials and methods}

\subsection{Waste characterization}

WFO, mainly composed by sunflower oil, was collected from a domestic kitchen in Braga (Portugal), filtered twice to remove remaining food particles and stored at $6{ }^{\circ} \mathrm{C}$. The WFO was characterized in terms of chemical oxygen demand (COD, $2.3 \pm 0.5 \mathrm{~g} \mathrm{~g}^{-1}$ ), free LCFA content and total (free + glycerol-bonded) LCFA content (Table 1). Medium chain fatty acids (MCFA, C6-C12) were also analysed but were not detected or were below the detection limit $\left(<20 \mathrm{mg} \mathrm{L}^{-1}\right)$. The presence of shorter chain fatty acids was not evaluated since the oil is not soluble in water and therefore cannot be analysed by HPLC. WFO was mainly composed of unsaturated LCFA (linoleate and oleate), which represented $88 \%$ of the total LCFA quantified. This agrees well with the fact that the WFO used in this study was composed mainly by sunflower oil, which usually contains mainly longer fatty acids ( $\geq$ C12) [19].

\subsection{Inoculum}

Anaerobic granular sludge ( $10 \mathrm{~g} \mathrm{~L}^{-1}$ of volatile solids (VS)) from a brewery wastewater treatment plant (Super Bock, Porto, Portugal) was disrupted to increase the surface area that would be in contact with the substrate, and was further acclimatized to WFO. For that, a $2.25 \mathrm{~L}$ bioreactor was operated for 60 days at approximately $37^{\circ} \mathrm{C}$. The reactor was fed twice per week with a mixture of the following components (concentrations in COD): WFO $\left(0.5 \mathrm{~g} \mathrm{~L}^{-1}\right)$, glycerol $\left(0.125 \mathrm{~g} \mathrm{~L}^{-1}\right)$, acetate $\left(0.125 \mathrm{~g} \mathrm{~L}^{-1}\right)$, butyrate $\left(0.125 \mathrm{~g} \mathrm{~L}^{-1}\right)$ and caprylate $\left(0.125 \mathrm{~g} \mathrm{~L}^{-1}\right)$, in a total of $1 \mathrm{~g} \mathrm{~L}^{-1}$ in COD. The same volume as the feed, was sampled for posterior analysis, and therefore the reactors working volume was kept constant over the time. In the first day of the reactor operation, sodium bicarbonate was added in a concentration of $3 \mathrm{~g} \mathrm{~L}^{-1}$, as well as micronutrients $\left(1 \mathrm{~mL} \mathrm{~L}^{-1}\right)$ and macronutrients supplemented with a nitrogen source ( $0.6 \mathrm{~mL}$ per $\mathrm{g}$ of COD fed) according to Alves et al. [20]. The mixing was promoted by liquid recirculation.

The two bioreactors used in the experiment were inoculated with a mixture of acclimatized and fresh sludge from the same origin (50:50\%, w/w in VS) at a final concentration of $10 \mathrm{~g} \mathrm{~L}^{-1}$ in VS. This mixture was prepared in tap water supplemented with micronutrients and macronutrients as previously described, and flushed with nitrogen to remove the residual oxygen. Since the $\mathrm{pH}$ was high ( $(9)$ in the acclimatization process, sodium bicarbonate was not added in the reactors start-up.

\subsection{Experimental set-up and operation mode}

The two bioreactors consisted of plexiglass cylinders (Fig. 1)

\section{Table 1}

Free and total LCFA composition of the WFO, presented in mg of LCFA per $g$ of WFO. Total LCFA as COD is presented in mg of COD per $g$ of WFO, and the \% of total LCFA is presented in $\mathrm{w} / \mathrm{w}$.

\begin{tabular}{|c|c|c|c|c|c|c|c|c|c|c|}
\hline \multirow[b]{3}{*}{ Linoleate } & \multirow{2}{*}{\multicolumn{3}{|c|}{$\begin{array}{c}\text { Free LCFA } \\
\left(\mathrm{mg} \mathrm{g}^{-1}\right)\end{array}$}} & \multirow{2}{*}{\multicolumn{3}{|c|}{$\begin{array}{c}\text { Total LCFA } \\
\left(\mathrm{mg} \mathrm{g}^{-1}\right)\end{array}$}} & \multirow{2}{*}{\multicolumn{3}{|c|}{$\begin{array}{c}\text { Total LCFA (as } \\
\text { COD) } \\
\left(\mathrm{mg} \mathrm{g}^{-1}\right)\end{array}$}} & \multirow{3}{*}{$\begin{array}{l}\text { Total LCFA } \\
(\%) \\
60\end{array}$} \\
\hline & & & & & & & & & & \\
\hline & 75 & \pm & 21 & 524 & \pm & 43 & 1498 & \pm & 124 & \\
\hline Oleate & 20 & \pm & 2 & 241 & \pm & 42 & 695 & \pm & 122 & 28 \\
\hline Stearate & 6 & \pm & 0 & 42 & \pm & 13 & 124 & \pm & 37 & 5 \\
\hline Palmitate & 8 & \pm & 0 & 65 & \pm & 6 & 187 & \pm & 16 & 7 \\
\hline
\end{tabular}



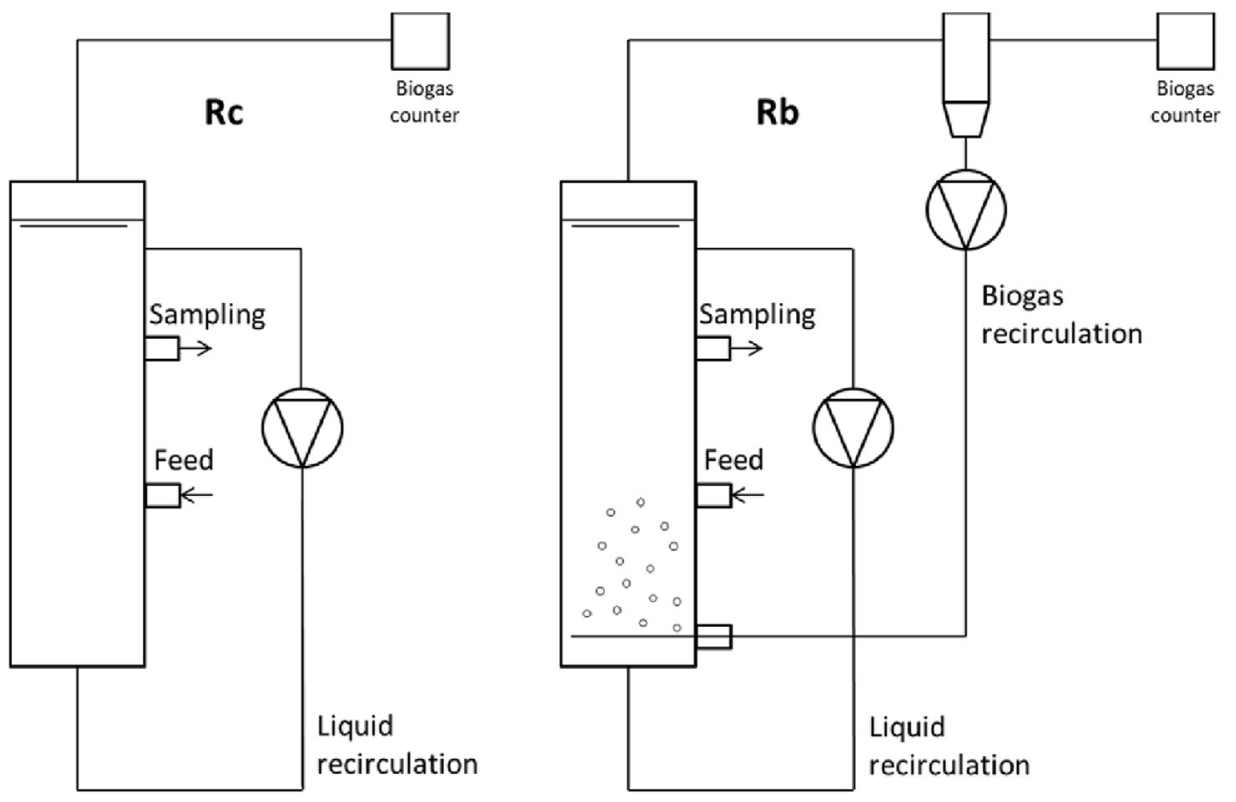

Fig. 1. Rc and Rb bioreactors configuration.

with a total volume of $2.25 \mathrm{~L}$ and a working volume of $2 \mathrm{~L}$, and were operated in parallel at mesophilic temperature $(37 \pm 2){ }^{\circ} \mathrm{C}$. The reactors had an internal diameter of $6.5 \mathrm{~cm}$, an external diameter of $9 \mathrm{~cm}$, a high of approximately $77 \mathrm{~cm}$, and a conical structure in the bottom. During Period I of operation (0-7 days), both reactors had internal liquid recirculation; in Period II (7-30 days), besides the liquid recirculation, part of the biogas produced in $\mathrm{Rb}$ was collected and re-injected near the bottom of the reactor (at $62 \mathrm{~cm}$ from the top of the reactor) with a peristaltic pump $\left(37 \mathrm{~mL} \mathrm{~min}^{-1}\right)$. Since the mixing flow in $\mathrm{Rb}$ was higher, due to the combined effect of the biogas (37 $\left.\mathrm{mL} \mathrm{min}^{-1}\right)$ and liquid $\left(210 \mathrm{~mL} \mathrm{~min}^{-1}\right)$ recirculation, the Rc liquid recirculation was adjusted to the same total flow rate value (i.e., $247 \mathrm{~mL} \mathrm{~min}^{-1}$ ) at day 18 .

Both reactors were intermittently fed 3 times per week with a mixture of WFO, glycerol, a VFA mixture and caprylate, as it was previously described in the acclimatization process. Liquid $(10 \mathrm{~mL})$ samples were collected at the sampling port (Fig. 1), each time before the feeding, and then the same volume of the mixture containing WFO + glycerol + VFA was fed to the reactors, keeping reactor's working volume constant. The cumulative biogas production was followed during the experiment and the methane content was measured 3 times per week. VFA, soluble COD and free and total LCFA in reactor's media were analysed.

\subsection{Analytical methods}

Biogas production was measured with a Ritter MilliGascounter (Dr.-Ing. Ritter Apparatebau GmbH, Bochum, Germany). The percentage of $\mathrm{CH}_{4}$ present in the biogas was determined in a gas chromatograph GC Chrompack 9000 (Shimadzu, Kyoto, Japan), equipped with a PoraPack Q column, 80/100 mesh, $2 \mathrm{~m} \mathrm{x} 0.125$ in $\mathrm{x}$ $2 \mathrm{~mm}$, in stainless steel. The temperature of the column, injector and flame ionization detector (FID) was respectively $35^{\circ} \mathrm{C}, 110{ }^{\circ} \mathrm{C}$ and $220^{\circ} \mathrm{C}$. Nitrogen flow was set at $30 \mathrm{~mL} \mathrm{~min}^{-1} .500 \mu \mathrm{l}$ of biogas were withdrawn from a sampling points using a graduated gas tight syringe. A known gas mixture containing $40 \%$ of methane was used as standard. Samples were analysed in triplicate.

VFAs concentrations were determined by HPLC (Jasco, Tokyo, Japan) with UV detector at $\lambda=210 \mathrm{~nm}$ and a column Rezex
ROA_Organic Acid H+ (300 mm $\times 7.8 \mathrm{~mm})$ (Phenomenex, CA, USA), operated at an oven temperature of $60{ }^{\circ} \mathrm{C} . \mathrm{H}_{2} \mathrm{SO}_{4}\left(2.5 \mathrm{mmol} \mathrm{L}^{-1}\right)$ was used as eluent; crotonic acid was used as internal standard (IS). The samples were previously centrifuged (10 min, 20,000 g) and frozen until the moment of analysis.

Gas Chromatography (GC) was used for MCFA and LCFA detection and quantification (from C6 to C18:2 acids). Regarding free MCFA and LCFA, esterification in the presence of $\mathrm{HCl} / 1$-propanol $(25: 75 \%, v / v)$ was performed at $100{ }^{\circ} \mathrm{C}$ for $3.5 \mathrm{~h}$. Then, dichloromethane was used to extract the propyl-esters that were further quantified by GC according to Neves et al. [21]. The GC-FID (VARIAN 3800) was equipped with a FID, and the fatty acids (FA) were separated using a Teknokroma TRB-WAX column (Teknokroma Analítica, Barcelona, Spain) with helium as the carrier gas at $1 \mathrm{~mL} \mathrm{~min}^{-1}$. The air flow was set at $250 \mathrm{~mL} \mathrm{~min}^{-1}$; nitrogen and

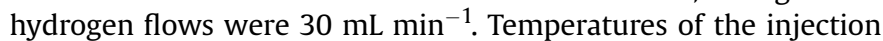
port and detector were 220 and $250{ }^{\circ} \mathrm{C}$, respectively. Initial oven temperature was $50{ }^{\circ} \mathrm{C}$ for $2 \mathrm{~min}$, with a $10{ }^{\circ} \mathrm{C} \mathrm{min}{ }^{-1}$ ramp to $225^{\circ} \mathrm{C}$, and a final isothermal for $10 \mathrm{~min}$. FA concentrations obtained from GC analysis were converted to its equivalent COD. For the total (free and glycerol-bonded) MCFA and LCFA quantification, hydrolysis and FA methylation was promoted using a mixture of methanol/sulfuric acid $(85: 15 \%, v / v)$ for $3.5 \mathrm{~h}$ at $100^{\circ} \mathrm{C}$ [22]. Further extraction was performed with chloroform. The methyl esters were analysed in a GC-FID (Varian 3800) under the same conditions as previously described for free FA.

COD was analysed in samples previously centrifuged at $20,000 \mathrm{~g}$ for $10 \mathrm{~min}$, using cuvette test kits (Hach Lange, Düsseldorf, Germany) and a DR 2800 spectrophotometer (Hach-Lange GmbH). Total solids (TS), volatile solids (VS), total suspended solids (TSS) and volatile suspended solids (VSS) were determined gravimetrically [23]. pH was measured with HANNA HI83141 pH meter.

\subsection{Specific methanogenic activity (SMA) tests}

The specific acetoclastic methanogenic activity (SAMA) and the hydrogenotrophic methanogenic activity (SHMA) of the sludge were assessed at the beginning (previously to acclimatization) and at the end of the reactors operation, according with the procedure 
described by Alves et al. [20], using $\mathrm{Na}_{2} \mathrm{~S}\left(1 \mathrm{mmol} \mathrm{L}^{-1}\right)$ as reducing agent. Acetate concentration was $30 \mathrm{mmol} \mathrm{L}^{-1}$ and the gaseous substrate was a gas mixture of $\mathrm{H}_{2} / \mathrm{CO}_{2}(80: 20 \%, \mathrm{v} / \mathrm{v}, 202.65 \mathrm{kPa})$. A pressure transducer was used to measure the pressure increase resulted from methane production in SAMA and pressure decrease from hydrogen consumption in SHMA [24]. Methane and VS content of each vial was measured at the end of the tests, as described in the analytical methods section. The specific methanogenic activity was expressed in volume of methane produced, at standard temperature and pressure (STP) conditions, per mass unit of VS of inoculum and time $\left(\mathrm{mL} \cdot \mathrm{g}^{-1} \cdot \mathrm{d}^{-1}\right)$.

\subsection{Homoacetogenic activity}

A batch test, similar to the SHMA described previously, was performed to evaluate homoacetogenic activity. For that, $20 \mathrm{mmol} \mathrm{L}^{-1}$ of 2-bromoethanesulfonate (BrES) were added to inhibit the methanogens [25]. Hydrogen consumption was followed as described for the SHMA tests using a pressure transducer. In the end of the assays, acetate and methane concentrations were measured.

\subsection{RNA extraction and $16 S$ rRNA gene sequencing}

At the end of the reactors operation, samples were immediately centrifuged ( $4000 \mathrm{~g}$ for $8 \mathrm{~min}$ ). The supernatant was removed, and the pellet was suspended in RNAlater (Sigma) and stored at $-20^{\circ} \mathrm{C}$. Total RNA was extracted using FastRNAPro Soil-Direct Kit (MP Biomedicals) and then digested with RNase-free DNase I (Invitrogen, Carlsbad, CA). DNA-free RNA was used as template for complementary DNA (cDNA) synthesis using a SuperScript reverse transcriptase III (Invitrogen, Carlsbad, CA), and purified by ethanol precipitation. The cDNA amplification, Illumina libraries preparation, amplicon sequencing (Illumina MiSeq, Inc. SanDiego, California) and bioinformatics analysis of the data were performed at Research and Testing Laboratory (RTL, Texas). Samples were amplified for sequencing using the universal primer pair, 515f and 806r, targeting the prokaryotic 16S rRNA gene [26]. After the sequencing process has been completed, the data analysis pipeline processed the data in two major stages, the denoising and chimera detection stage and the microbial diversity analysis stage, as described in the company report [27]. The FASTQ files were submitted in the European Nucleotide Archive (ENA), being available in the following link http://www.ebi.ac.uk/ena/data/view/ PRJEB35336. Nucleotide sequences are identified with accession numbers ERS3968438 to ERS3968441.

\subsection{Statistical analysis}

Statistical significance of the differences in the percentage of COD recovered as methane in the bioreactors, as well as of the differences in acetate production in the homoacetogenic activity test, was evaluated using single factor analysis of variances (ANOVA). Statistical significance was established at the $p<0.05$ level.

\section{Results}

Reactors operation was divided in two periods: Period I, in which reactors $\mathrm{Rb}$ and $\mathrm{Rc}$ had only liquid recirculation; and Period II, in which biogas recirculation was also applied to reactor $\mathrm{Rb}$. In Period I and during the first seven days of period II (i.e., between days 7-14 of operation), both reactors presented similar biogas production (Fig. 2a). On day 18 the total recirculation flow (gas + liquid in $\mathrm{Rb}$; liquid in $\mathrm{Rc}$ ) was equalized in both reactors.
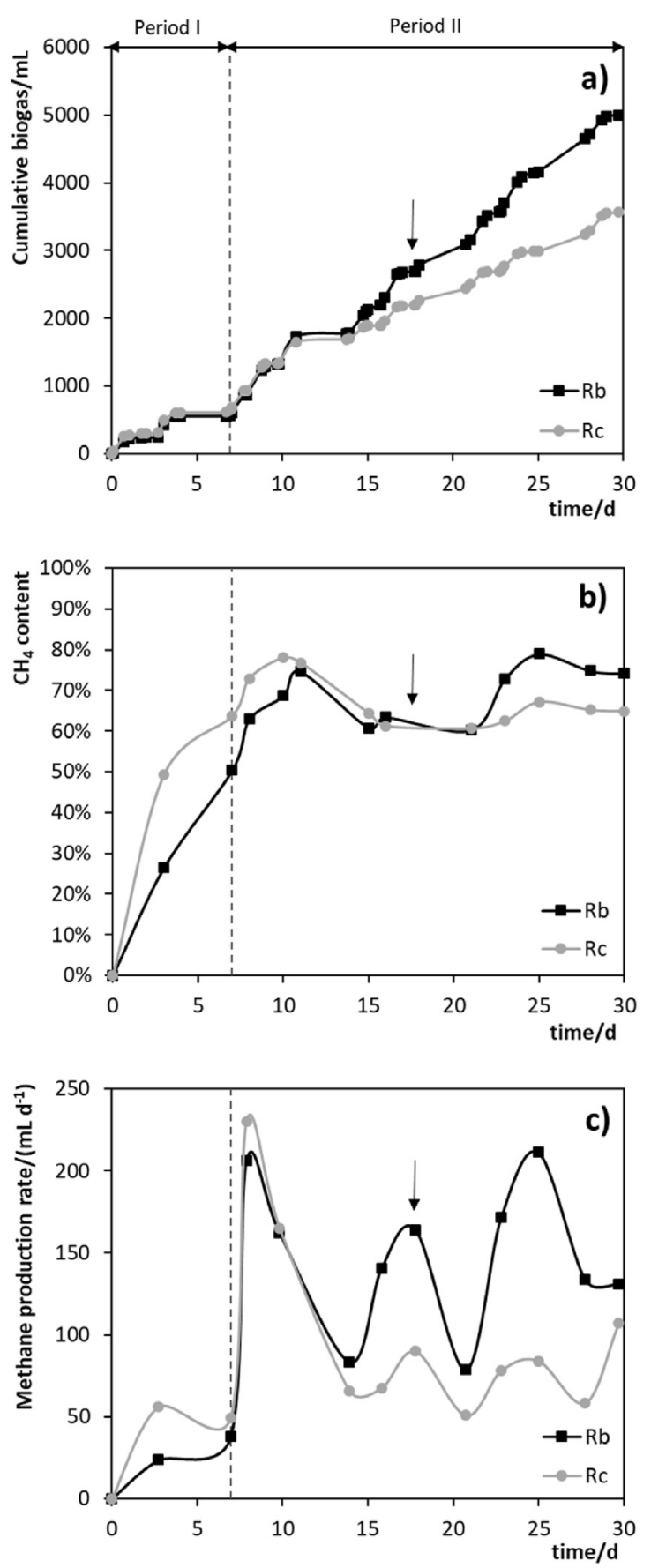

Fig. 2. Cumulative methane production (a), methane content (b) and methane production rate (c) in reactors $\mathrm{Rb}$ and $\mathrm{Rc}$. The black arrow indicates the moment when the total recirculation flow (gas + liquid in $\mathrm{Rb}$; liquid in $\mathrm{Rc}$ ) was equalized in both reactors.

After that and until the end of the experiment, Rb presented higher cumulative biogas production (Fig. 2a) with higher methane content (Fig. 2b), reaching a maximum value of $79 \%$ at day 25 . Higher methane production rates were also obtained in $\mathrm{Rb}$ relatively to $\mathrm{Rc}$ in this time period (Fig. 2c), with maximum values around $200 \mathrm{~mL} \mathrm{~d}^{-1}$ and $100 \mathrm{~mL} \mathrm{~d}^{-1}$, respectively (Fig. 2c).

Soluble COD was determined in both reactors before each feeding, and the results were rather stable over time: $(278 \pm 26) \mathrm{mg}$ $\mathrm{L}^{-1}$ and $(275 \pm 24) \mathrm{mg} \mathrm{L}^{-1}$ in $\mathrm{Rb}$ and in Rc during the whole operation. Comparing the methane produced from each pulse of substrate, it is possible to observe that more COD was recovered as 
methane in $\mathrm{Rb}$ than in Rc (Table 2). In particular, from day 18 (when the total recirculation flow was equalized in both reactors) until the end of the experiment, the percentage of methane recovered in the $\mathrm{Rb}(45 \pm 10 \%)$ was significantly higher $(p<0.05)$ than in the $\mathrm{Rc}$ $(22 \pm 2 \%)$.

Over the operation time no VFA accumulation was observed in both reactors. Free LCFA (oleate) accumulated in Rb by the end of Period I (Fig. 3), but right after day 7, none LCFA was detected until day 18. After this day, transient palmitate accumulation occurred in $\mathrm{Rb}$, reaching $71 \mathrm{mg} \mathrm{L}^{-1}$ (in COD) at day 23. In Rc, palmitate started accumulating at day 21 , reaching a maximum value of $122 \mathrm{mg} \mathrm{L}^{-1}$ (in COD) at day 28. At the end of the experiment, also oleate (101 $\mathrm{mg} \mathrm{L}^{-1}$ in COD) accumulated in Rc, corresponding to a total LCFA concentration (in COD) of $223 \mathrm{mg} \mathrm{L}^{-1}$. Regarding the total (free + glycerol-bonded) LCFA, linoleate and oleate were the main acids present and their concentration was quite stable over the time: linoleate concentration (in COD) was $119 \pm 15 \mathrm{mg} \mathrm{L}^{-1}$ and $120 \pm 5 \mathrm{mg} \mathrm{L}^{-1}$ in $\mathrm{Rb}$ and $\mathrm{Rc}$, respectively; oleate concentration was $96 \pm 34 \mathrm{mg} \mathrm{L}^{-1}$ and $107 \pm 25 \mathrm{mg} \mathrm{L}^{-1}$ in $\mathrm{Rb}$ and Rc, respectively. These values point to the occurrence of hydrolysis, circa $58 \%$ and $55 \%$ of the added WFO in $\mathrm{Rb}$ and Rc, respectively.

$\mathrm{pH}$ values were similar in both reactors over the two periods, around $8.5 \pm 0.2$ in $\mathrm{Rb}$ and $8.5 \pm 0.1$ in Rc.

At the end of the reactor's operation, the specific hydrogenotrophic methanogenic activity (SHMA) was slightly higher in $\mathrm{Rb}$ than in Rc (Table 3). Regarding the specific acetoclastic methanogenic activity (SAMA), low values were obtained for both reactors (Table 3 ). In the homoacetogenic activity tests, sludge from $\mathrm{Rb}$ produced significantly more $(p<0.05)$ acetate from hydrogen after 5 days of incubation than the Rc sludge (i.e., $2651 \pm 31 \mathrm{mg} \mathrm{L}^{-1}$ and $2424 \pm 59 \mathrm{mg} \mathrm{L}^{-1}$, respectively).

The microbial communities' composition was also analysed at the end of the reactors operation (Table 4). The main differences in the relative microbial abundance were in the Methanomicrobiales order, which comprises hydrogenotrophic methanogenic archaea [28], corresponding to $16-20 \%$ in $\mathrm{Rb}$ and $4-10 \%$ in Rc, the class Spirochaetia representing approximately $17 \%$ in $\mathrm{Rb}$ and $7 \%$ in $\mathrm{Rc}$, and the Methanosaeta genus (acetoclastic methanogens) that represents $8-10 \%$ and $2-5 \%$ in $\mathrm{Rb}$ and $\mathrm{Rc}$, respectively.

Analysing only the archaeal community (Fig. 4), it is possible to see that the Methanomicrobiales are the second dominant order, representing 33-46\% of the archaea in Rb and 19-35\% in Rc reactor. At the genera level, the most dominant were Methanobacterium with $31-48 \%$ in $\mathrm{Rb}$ and $40-66 \%$ in Rc, and Methanosaeta being $17-22 \%$ and $10-19 \%$ of the archaeal community in Rb and Rc, respectively.

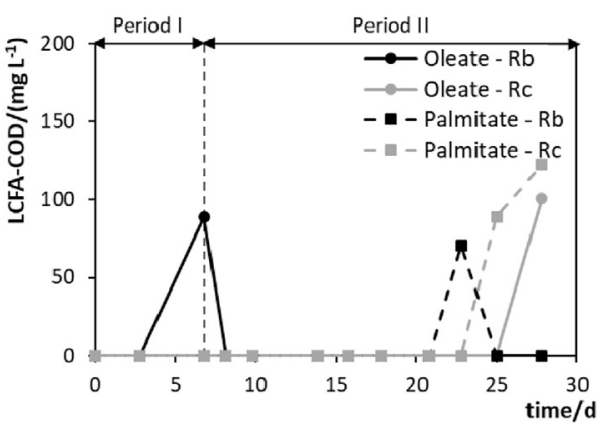

Fig. 3. Free LCFA content (expressed in COD) in reactors $\mathrm{Rb}$ and Rc.

Table 3

Specific methanogenic activity of the sludge from $\mathrm{Rb}$ and Rc bioreactors, at the end of the experiment.

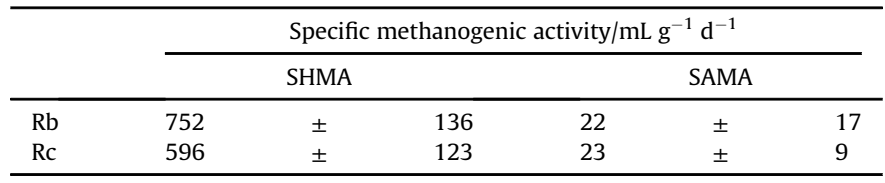

\section{Discussion}

Mixing is an important parameter in the $A D$ of wastewater containing lipids, since it promotes the contact between substrate and microorganisms inside the digester [29]. During starch fermentation for bio-ethanol production, mixing induced by gas recirculation has been described as more efficient than by liquid recirculation [30]. Additionally, besides contributing for mixing, biogas recirculation is also expected to contribute for biogas upgrading. In this work, biogas recirculation was successfully applied to promote WFO degradation and biogas upgrading (Fig. 2), enabling 1.4 times higher cumulative biogas/methane production from the substrates fed, relatively to a similar system operated without biogas recirculation. Moreover, comparing the COD fed in each pulse with the cumulative methane production (Table 2), $(45 \pm 10) \%$ of the COD fed was recovered as methane in the Rb, while only $(22 \pm 2) \%$ was recovered in the Rc, from days $18-28$. In this time period, remaining COD could be found in the nonhydrolysed portion of WFO (approx. 21-23\% of the total COD fed in both reactors) and in the soluble COD present in the reactors before each new feeding ( $25 \%)$. In Rc, these values were also complemented with the accumulated free LCFA (Fig. 3), which

Table 2

Total COD fed in each pulse, the methane produced (in $\mathrm{g}$ of COD) and the respective \% of COD recovered as methane.

\begin{tabular}{|c|c|c|c|c|c|c|}
\hline \multirow{3}{*}{ Time (d) } & \multicolumn{3}{|l|}{$\mathrm{Rb}$} & \multicolumn{3}{|l|}{ Rc } \\
\hline & COD fed & $\mathrm{CH}_{4}-\mathrm{COD}$ & COD recovered as $\mathrm{CH}_{4}$ & COD fed & $\mathrm{CH}_{4}-\mathrm{COD}$ & COD recovered as $\mathrm{CH}_{4}$ \\
\hline & (g) & (g) & (\%) & (g) & (g) & (\%) \\
\hline 0 & 2.22 & 0.00 & 0 & 2.04 & 0.00 & 0 \\
\hline 3 & 2.19 & 0.19 & 8 & 2.13 & 0.44 & 22 \\
\hline 7 & 2.17 & 0.45 & 21 & 2.14 & 0.60 & 28 \\
\hline 8 & 2.09 & 0.55 & 25 & 2.13 & 0.62 & 29 \\
\hline 10 & 2.11 & 0.90 & 43 & 2.11 & 0.92 & 43 \\
\hline 14 & 2.09 & 0.98 & 46 & 2.02 & 0.77 & 36 \\
\hline 16 & 2.25 & 0.75 & 36 & 2.16 & 0.36 & 18 \\
\hline 18 & 2.16 & 0.94 & 42 & 2.03 & 0.51 & 24 \\
\hline 21 & 2.21 & 0.66 & 31 & 2.17 & 0.43 & 21 \\
\hline 23 & 2.31 & 1.02 & 46 & 2.15 & 0.46 & 21 \\
\hline 25 & 2.12 & 1.32 & 57 & 2.09 & 0.52 & 24 \\
\hline 28 & 2.12 & 1.05 & 49 & 2.05 & 0.46 & 22 \\
\hline
\end{tabular}


Table 4

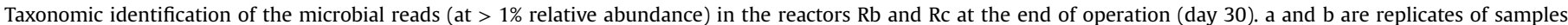
collected from the same reactor.

\begin{tabular}{|c|c|c|c|c|c|c|c|}
\hline \multirow[t]{2}{*}{ Phylum } & \multirow[t]{2}{*}{ Class } & \multirow[t]{2}{*}{ Order } & \multirow[t]{2}{*}{ Genus } & \multicolumn{2}{|c|}{$\mathrm{Rb} / \%$} & \multicolumn{2}{|c|}{$\mathrm{Rc} / \%$} \\
\hline & & & & $\mathrm{a}$ & $\mathrm{b}$ & $\mathrm{a}$ & $\mathrm{b}$ \\
\hline Euryarchaeota & Methanobacteria & Methanobacteriales & Methanobacterium & 23 & 14 & 11 & 12 \\
\hline Euryarchaeota & Methanomicrobia & Methanomicrobiales & Unclassified & 16 & 20 & 10 & 4 \\
\hline Spirochaetes & Spirochaetia & Unclassified & Unclassified & 17 & 18 & 7 & 7 \\
\hline Proteobacteria & Deltaproteobacteria & Syntrophobacterales & Syntrophobacter & 5 & 3 & 6 & 11 \\
\hline Euryarchaeota & Methanomicrobia & Methanosarcinales & Methanosaeta & 8 & 10 & 5 & 2 \\
\hline Proteobacteria & Betaproteobacteria & Rhodocyclales & Azoarcus & $<1$ & $<1$ & 5 & 3 \\
\hline Proteobacteria & Gammaproteobacteria & Pseudomonadales & Pseudomonas & 0 & 0 & 3 & 5 \\
\hline Planctomycetes & Phycisphaerae & Unclassified & Unclassified & 3 & 2 & 3 & 2 \\
\hline Proteobacteria & Deltaproteobacteria & Syntrophobacterales & Syntrophus & $<1$ & $<1$ & 2 & 2 \\
\hline Proteobacteria & Deltaproteobacteria & Desulfuromonadales & Geobacter & $<1$ & $<1$ & 2 & 5 \\
\hline Firmicutes & Bacilli & Lactobacillales & Trichococcus & 2 & 2 & 2 & 4 \\
\hline Proteobacteria & Deltaproteobacteria & Syntrophobacterales & Smithella & $<1$ & $<1$ & 2 & 1 \\
\hline Proteobacteria & Unclassified & Unclassified & Unclassified & $<1$ & $<1$ & 1 & 2 \\
\hline Planctomycetes & Planctomycetia & Unclassified & Unclassified & $<1$ & $<1$ & 1 & $<1$ \\
\hline Unclassified & Unclassified & Unclassified & Unclassified & $<1$ & $<1$ & 1 & $<1$ \\
\hline Proteobacteria & Gammaproteobacteria & Methylococcales & Methylomonas & $<1$ & $<1$ & $<1$ & 1 \\
\hline Spirochaetes & Spirochaetia & Unclassified & Leptospira & 1 & 1 & $<1$ & $<1$ \\
\hline Proteobacteria & Epsilonproteobacteria & Campylobacterales & Sulfurimonas & 0 & 0 & $<1$ & 2 \\
\hline Proteobacteria & Deltaproteobacteria & Desulfuromonadales & Unclassified & $<1$ & 1 & $<1$ & $<1$ \\
\hline Unclassified & Unclassified & Unclassified & Unclassified & 16 & 18 & 23 & 21 \\
\hline
\end{tabular}

represented around $21 \%$ in COD.

Considering that only a small portion of free LCFA was present in the WFO (Table 1), and that the free LCFA concentrations measured in Rc were higher than that (Fig. 3), LCFA degradation appears to be the limiting step in the conversion of WFO to methane. These results are also supported by the fact that, despite both reactors had the same recirculation flow rate (from day 18 on), whitish particles could be observed in Rc at the end of the operation (Figure S1), which suggested the presence of LCFA [14]. That did not occur in Rb. Although linoleate was the predominant LCFA present in the WFO, representing $60 \%$ of total LCFA, it was not detected as free LCFA (Fig. 3), while palmitate (in the free form) was detected at higher concentrations than those of the WFO (Fig. 3, Table 1), which suggests the occurrence of incomplete LCFA conversion in Rc.

In the two reactors there was no VFA accumulation, showing the ability of both microbial communities to degrade these compounds. Moreover, similar WFO hydrolysis was obtained in Rb and Rc (i.e., $55-58 \%$ of the WFO fed, which corresponds to $27-29 \%$ of the total COD fed). Therefore, the positive effect of biogas recirculation seems to be related with enhanced LCFA biodegradation.

The $\mathrm{Rb}$ sludge presented a higher SHMA (Table 3), as well as a higher relative abundance of archaea (44-47\%) in the total microbial community, and in particular hydrogenotrophic methanogens (sum of relative abundances of Methanobacterium genus and Methanomicrobiales order, 34-39\%, Table 4), when compared with the Rc community (18-26\% and $16-21 \%$ relative abundances for archaea and hydrogenotrophic methanogens, respectively, Table 4). These results suggest that biogas recirculation promoted biogas upgrading by stimulating the growth of hydrogenotrophic methanogens. This was probably associated with faster hydrogen consumption, that represents an advantage for syntrophic relationships and may explain the enhanced LCFA biodegradation verified in $\mathrm{Rb}$.

Besides the effects already mentioned, it is also possible that biogas recirculation promotes the growth of homoacetogenic bacteria. In fact, when the methanogenic activity of both sludges was inhibited by BrES in batch vials, the microbial community of Rb exhibited a higher homoacetogenic activity than that of Rc. Additionally, the class Spirochaetia represented $17 \%$ of the Rb microbial community (more than the double than in Rc), which includes bacteria that are able to perform reductive acetogenesis from $\mathrm{H}_{2}$ and $\mathrm{CO}_{2}$, such as the ones belonging to Triponema genus [31,32].

In the recent years, biogas upgrading has been under study mainly with focus on addition of exogenous $\mathrm{H}_{2} / \mathrm{CO}_{2}$ to $\mathrm{AD}$ systems [4]. Usually in those systems, when exogenous $\mathrm{H}_{2} / \mathrm{CO}_{2}$ was added (high $\mathrm{H}_{2}$ partial pressure, $96 \mathrm{kPa}$ ), hydrogenotrophic methanogens and homoacetogens contributed $60 \%$ and $40 \%$, respectively, to the hydrogen consumption [33]. However, at a low $\mathrm{H}_{2}$ partial pressure (1-10 Pa), as typically found in natural anaerobic environments and in ordinary anerobic digestors, hydrogenotrophic methanogens are usually the superior competitors for $\mathrm{H}_{2}$ consumption [34]. This can be explained by the fact that methane formation from $\mathrm{H}_{2} / \mathrm{CO}_{2}$ is thermodynamically more favorable $\left(\Delta G^{0^{\prime}}=-131.0 \mathrm{~kJ}\right.$ reaction $\left.{ }^{-1}\right)$ than acetate formation $\left(\Delta G^{0^{\prime}}=-94.5 \mathrm{~kJ}\right.$ reaction $\left.^{-1}\right)$ from the same substrate [35].

Homoacetogenic bacteria convert $\mathrm{CO}_{2}$ to acetate via the WoodLjungdahl pathway, that may be further converted to $\mathrm{CH}_{4}$ by acetoclastic methanogenesis [4]. Nevertheless, the sludge from both reactors presented similar values of SAMA (Table 3), and these values were relatively low. Some homoacetogenic bacteria are also capable of performing syntrophic acetate oxidation, thus reversing their homoacetogenic metabolism towards acetate oxidation to hydrogen and carbon dioxide [22], that can be further consumed by hydrogenotrophic methanogens. In fact, reversed homoacetogenesis has been reported when these bacteria are growing in syntrophy with methanogens [36]. Moreover, Lee et al. [37] provided evidence of syntrophic acetate oxidation by cluster II Spirochaetes during anaerobic methane production. Therefore, the role of homoacetogenic bacteria in WFO degradation is not clear, and may include both acetate formation or/and degradation. In this last case, hydrogen is formed, which probably contributed for the increased hydrogenotrophic methanogenesis verified in $\mathrm{Rb}$.

\section{Conclusions}

This work has shown that biogas recirculation not only improved LCFA conversion, which was the rate limiting step in WFO degradation, but also promoted the biogas upgrading, enabling 1.4 times higher cumulative biogas/methane production, relatively to a 

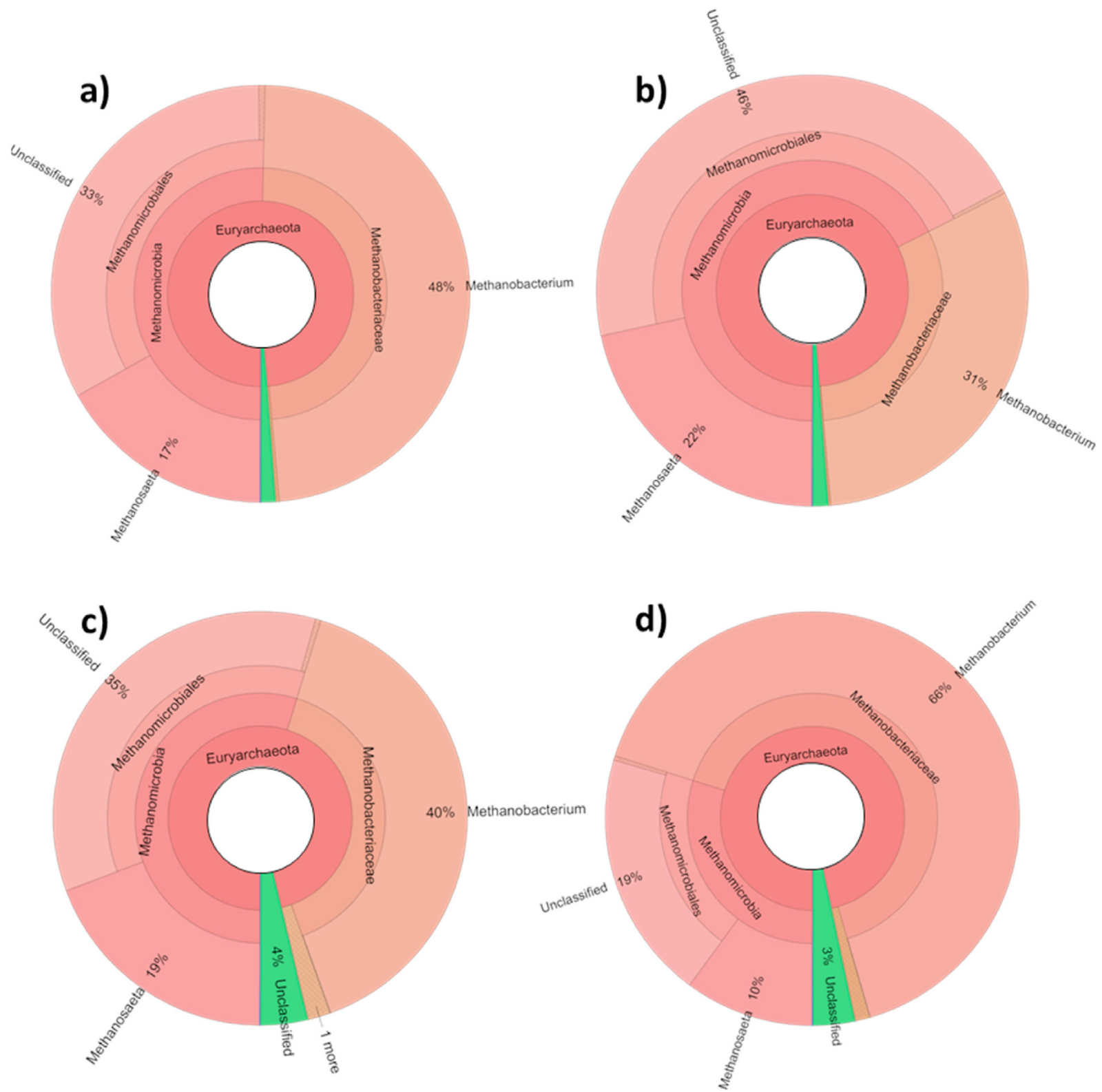

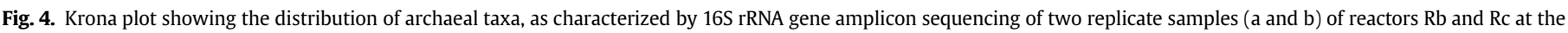
end of the experiment (day 30). a) Rb-a; b) Rb-b; c) Rc-a; d) Rc-b.

similar system operated without biogas recirculation. This was assigned to the enhancement of the activity and presence of hydrogenotrophic methanogens $(34 \%-39 \%$ in Rb, while only $16 \%-$ $21 \%$ in $\mathrm{Rc}$ ), induced by the recirculation of $\mathrm{CO}_{2}$ present in the biogas, as well as by the activity of homoacetogenic/syntrophic acetate oxidizing bacteria, ultimately resulting in upgraded biogas.

In conclusion, biogas recirculation can be a practical and costeffective method to increase biogas production and its methane content, and can be used as an innovative technique for increased energy recovery and biogas upgrading from lipid-rich waste (water)s.

\section{CRediT authorship contribution statement}

M. Salomé Duarte: Data curation, Methodology, Writing original draft. Erika Sinisgalli: Data curation, Methodology, Writing - original draft. Ana J. Cavaleiro: Methodology, Data curation, Writing - review \& editing. Lorenzo Bertin: Conceptualization, Writing - review \& editing. M. Madalena Alves: Supervision, Writing - review \& editing. M. Alcina Pereira: Conceptualization, Supervision, Writing - review \& editing.

\section{Declaration of competing interest}

The authors declare that they have no known competing financial interests or personal relationships that could have appeared to influence the work reported in this paper.

\section{Acknowledgements}

This study was supported by the Portuguese Foundation for Science and Technology (FCT) under the scope of the strategic funding of UIDB/04469/2020 unit and BioTecNorte operation (NORTE-01-0145-FEDER-000004) funded by the European 
Regional Development Fund under the scope of Norte2020 - Programa Operacional Regional do Norte.

\section{Appendix A. Supplementary data}

Supplementary data to this article can be found online at https://doi.org/10.1016/j.renene.2020.12.114.

\section{References}

[1] United Nations, The united nations sustainable development goals. https:// sustainabledevelopment.un.org/?menu=1300, 2015. (Accessed 16 February 2020).

[2] P.G. Kougias, L. Treu, D.P. Benavente, K. Boe, S. Campanaro, I. Angelidaki, Exsitu biogas upgrading and enhancement in different reactor systems, Bioresour, Technol. 225 (2017) 429-437.

[3] B. Omar, M. El-Gammal, R. Abou-Shanab, I.A. Fotidis, I. Angelidaki, Y. Zhang, Biogas upgrading and biochemical production from gas fermentation: impact of microbial community and gas composition, Bioresour. Technol. 286 (2019) 121413.

[4] I. Angelidaki, L. Treu, P. Tsapekos, G. Luo, S. Campanaro, H. Wenzel, P.G. Kougias, Biogas upgrading and utilization: current status and perspectives, Biotechnol. Adv. 36 (2018) 452-466.

[5] C. Chao, Y. Deng, R. Dewil, J. Baeyens, X. Fan, Post-combustion carbon capture, Renew. Sustain. Energy Rev. (2020) 110490.

[6] S.R. Guiot, R. Cimpoia, G. Carayon, Potential of wastewater-treating anaerobic granules for biomethanation of synthesis gas, Environ. Sci. Technol. 45 (2011) 2006-2012.

[7] I. Bassani, P.G. Kougias, L. Treu, H. Porté, S. Campanaro, I. Angelidaki, Optimization of hydrogen dispersion in thermophilic up-flow reactors for ex situ biogas upgrading, Bioresour. Technol. 234 (2017) 310-319.

[8] D.G. Cirne, X. Paloumet, L. Björnsson, M.M. Alves, B. Mattiasson, Anaerobic digestion of lipid-rich waste-effects of lipid concentration, Renew. Energy 32 (2007) 965-975.

[9] R. Marchetti, C. Vasmara, L. Bertin, F. Fiume, Conversion of waste cooking oil into biogas: perspectives and limits, Appl. Microbiol. Biotechnol. 104 (2020) 2833-2856.

[10] K. Hanaki, T. Matsuo, M. Nagase, Mechanism of inhibition caused by longchain fatty acids in anaerobic digestion process, Biotechnol. Bioeng. 23 (1981) 1591-1610.

[11] C.M. Scrimgeour, J.L. Harwood, Fatty acid and lipid structure, in: F.D. Gunstone, J.L. Harwood, A.J. Dijkstra (Eds.), Lipid Handb, CRC Press Taylor \& Francis Group, Third, 2007, pp. 1-36.

[12] C. Weng, J.S. Jeris, Biochemical mechanisms in the methane fermentation of glutamic and oleic acids, Water Res. 10 (1976) 9-18.

[13] J.S. Jeris, P.L. McCarthy, The niochemistry of methane fermentation using C14 tracers, Water Pollut. Control Fed 37 (1965) 178-192.

[14] M.A. Pereira, O.C. Pires, M. Mota, M.M. Alves, Anaerobic biodegradation of oleic and palmitic acids: evidence of mass transfer limitations caused by long chain fatty acid accumulation onto the anaerobic sludge, Biotechnol. Bioeng. 92 (2005) 15-23.

[15] C.-S. Hwu, G. Molenaar, J. Garthoff, J.B. Van Lier, G. Lettinga, Thermophilic high-rate anaerobic treatment of wastewater containing long-chain fatty acids: impact of reactor hydrodynamics, Biotechnol. Lett. 19 (1997) 447-451.

[16] J. Lindmark, E. Thorin, R. Bel Fdhila, E. Dahlquist, Effects of mixing on the result of anaerobic digestion: Review, Renew. Sustain. Energy Rev. 40 (2014) 1030-1047.

[17] A.J.M. Stams, C.M. Plugge, Electron transfer in syntrophic communities of anaerobic bacteria and archaea, Nat. Rev. Microbiol. 7 (2009) 568-577.

[18] M.M. Alves, M.A. Pereira, D.Z. Sousa, A.J. Cavaleiro, M. Picavet, H. Smidt,
A.J.M. Stams, Waste lipids to energy: how to optimize methane production from long-chain fatty acids (LCFA), Microb. Biotechnol. 2 (2009) 538-550.

[19] J. Orsavova, L. Misurcova, J. Vavra Ambrozova, R. Vicha, J. Mlcek, Fatty acids composition of vegetable oils and its contribution to dietary energy intake and dependence of cardiovascular mortality on dietary intake of fatty acids, Int. J. Mol. Sci. 16 (2015) 12871-12890.

[20] M. Alves, J. Mota Vieira, R. Álvares Pereira, M. Pereira, M. Mota, Effect of lipids and oleic acid on biomass development in anaerobic fixed-bed reactors. Part I: biofilm growth and activity, Water Res. 35 (2001) 255-263.

[21] L. Neves, M.A. Pereira, M. Mota, M.M. Alves, Detection and quantification of long chain fatty acids in liquid and solid samples and its relevance to understand anaerobic digestion of lipids, Bioresour. Technol. 100 (2009) 91-96.

[22] H. Brandl, R.A. Gross, R.W. Lenz, R.C. Fuller, Pseudomonas oleovorans as a source of poly( $\beta$-hydroxyalkanoates) for potential applications as biodegradable polyesters, Appl. Environ. Microbiol. 54 (1988) 1977-1982.

[23] APHA AWWA WPCF, Standard Methods for the Examination of Water and Wastewater, American P, Washington D.C., 1999.

[24] E. Colleran, F. Concannon, T. Golden, F. Geoghegan, B. Crumlish, E. Killilea, M. Henry, J. Coates, Use of methanogenic activity tests to characterize anaerobic sludges, screen for anaerobic biodegradability and determine toxicity thresholds against individual anaerobic trophic, Water Sci. Technol, 25 (1992) 31-40.

[25] A.A. Abreu, J.I. Alves, M.A. Pereira, D.Z. Sousa, M.M. Alves, Strategies to suppress hydrogen-consuming microorganisms affect macro and micro scale structure and microbiology of granular sludge, Biotechnol. Bioeng. 108 (2011) $1766-1775$.

[26] J.G. Caporaso, C.L. Lauber, W.A. Walters, D. Berg-Lyons, C.A. Lozupone, P.J. Turnbaugh, N. Fierer, R. Knight, Global patterns of 16S rRNA diversity at a depth of millions of sequences per sample, Proc. Natl. Acad. Sci. Unit. States Am. 108 (2011) 4516-4522.

[27] Research Testing Laboratory, Data Analysis Methodology for Microbial Diversity, 2014. http://www.researchandtesting.com/docs/Data_Analysis_ Methodology.pdf.

[28] W.E. Balch, G.E. Fox, LJ Magrum, C.R. Woese, R.S. Wolfe, Methanogens: reevaluation of a unique biological group, Microbiol. Rev. 43 (1979) 260-296.

[29] A. Sulaiman, M.A. Hassan, Y. Shirai, S. Abd-Aziz, M. Tabatabaei, Z. Busu, S. Yacob, The effect of mixing on methane production in a semi-commercial closed digester tank treating palm oil mill effluent, Aust. J. Basic Appl. Sci. 3 (2009) 1577-1583.

[30] H.L. Zhang, J. Baeyens, T.W. Tan, Mixing phenomena in a large-scale fermenter of starch to bio-ethanol, Energy 48 (2012) 380-391.

[31] W. Ikeda-Ohtsubo, J.F.H. Strassert, T. Köhler, A. Mikaelyan, I. Gregor, A.C. McHardy, S.G. Tringe, P. Hugenholtz, R. Radek, A. Brune, 'Candidatus Adiutrix intracellularis', an endosymbiont of termite gut flagellates, is the first representative of a deep-branching clade of Deltaproteobacteria and a putative homoacetogen, Environ. Microbiol. 18 (2016) 2548-2564.

[32] J.R. Leadbetter, T.M. Schmidt, J.R. Graber, J.A. Breznak, Acetogenesis from H2 plus CO2 by spirochetes from termite guts, Science 283 (1999) 686-689.

[33] R. Liu, X. Hao, J. Wei, Function of homoacetogenesis on the heterotrophic methane production with exogenous $\mathrm{H} 2 / \mathrm{CO} 2$ involved, Chem. Eng. J. 284 (2016) 1196-1203.

[34] O. Kotsyurbenko, Competition between homoacetogenic bacteria and methanogenic archaea for hydrogen at low temperature, FEMS Microbiol. Ecol. 38 (2001) 153-159.

[35] B. Schink, Energetics of syntrophic cooperation in methanogenic degradation, Microbiol. Mol. Biol. Rev. 61 (1997) 262-280.

[36] B. Müller, L. Sun, A. Schnürer, First insights into the syntrophic acetateoxidizing bacteria - a genetic study, Microbiology 2 (2013) 35-53.

[37] S.H. Lee, J.H. Park, S.H. Kim, B.J. Yu, J.J. Yoon, H.D. Park, Evidence of syntrophic acetate oxidation by Spirochaetes during anaerobic methane production, Bioresour. Technol. 190 (2015) 543-549. 